\title{
ROLE OF LIGAMENTUM FLAVECTOMY IN LUMBAR SPINAL CANAL STENOSIS
}

\author{
By
Kamal Abd El-Rahman Abd El-Hafez; Mohamad Fathy Fahmy El- Halawany and Mostafa Abd Allah Kamal Mostafa \\ Department of Orthopedic Surgery, Faculty of Medicine, Al-Azhar University \\ Corresponding author: Mostafa Abdallah Kamal Mostafa, \\ E-mail: drghost1989@gmail.com, Tel.: 01229090529
}

\begin{abstract}
Background: Lumbar spinal canal stenosis (LSCS) is a degenerative condition in which changes in the discs, ligamentum flavum, and facet joints with aging cause narrowing of the spaces around the neurovascular structures of the spine. These changes lead to pain in the legs and back, as well as impaired ambulation and other disabilities.
\end{abstract}

Objective: To provide an update review for determining the role of ligamentum flavectomy in lumbar spinal canal stenosis.

Patients and methods: This study was carried out as an interventional prospective study on 23 patients with lumbar spinal canal stenosis from August 2018 till August 2019. Study was conducted in Orthopedic Surgery Departments, EL-Sayed Galal and EL-Haram specialized Hospitals and aimed at assessment of the role of ligamentum flavectomy in lumbar spinal canal stenosis.

Results: The mean age was $50.5 \pm 5.7$ years ranging from 41 to 59 years. According to gender distribution, they were $13(56.5 \%)$ males, and $10(43.5 \%)$ females. The preoperative VAS ranged between 5-9 with mean $6.8 \pm 1.4$. Six weeks after operation its range became $1-5$ with mean $2.8 \pm 0.98$. Twelve weeks later, the range was $1-3$ with mean $1.7 \pm 0.7$. The preoperative ODI ranged between $3-46$ with mean $19.56 \pm 19.65$. Six weeks later, the range between $1-18$ with mean $7.3 \pm 7.26$. At twelve weeks, the range was between $1-15$ with mean $4.2 \pm 8.86$. At level L4/L5, ten patients (43.48\%) have lumbar stenosis. At L3/L4 and L4/L5 levels seven patients (30.42\%), and at L2/L3, L3/L4, L4/L5 levels six patients (26.1\%) have stenosis.

Conclusion: Ligamentum flavum hypertrophy is one of main causes of spinal canal stenosis so ligamentum flavectomy is an essential step in all surgical management of lumbar spinal canal stenosis for decompression of spinal canal.

Keywords: Ligamentum Flavectomy, Lumbar Spinal Canal Stenosis.

\section{INTRODUCTION}

Lumbar spinal canal stenosis (LSCS) is characterized by narrowing of the spinal canal with nerve root impingement, resulting in radiculopathy or pseudoclaudication. It results from intervertebral disc herniation and degenerative changes in the posterior structures of the lumbar spine, such as hypertrophy of the facet joints and ligamentum flavum (LF), and is more common in elderly patients. As the LF mostly covers the posterior and lateral parts of the lumbar spinal canal, its role in the pathogenesis of LF is crucial (Park et al., 2013).

However, the underlying mechanism remains unclear. The LF is composed of elastin and collagen fibers in a 2:1 ratio. 
The elastin fibers provide elasticity to the ligament, and the collagen fibers provide stiffness and stability (Park et al., 2009 and 2013). LF thickness is an agedependent and gender-independent phenomenon, and is correlated with disc degeneration, aging, BMI, LSCS, spinal level involved, and the presence of disc herniation (Altinkaya et al., 2011). Causes of spinal canal stenosis include central stenosis due to disc collapse and thickened LF, lateral or root canal stenosis, degenerative spondylolisthesis, metabolic causes, iatrogenic stenosis, spinal tumors, injury, Paget's disease of bone and achondroplasia. Methods of treatment include conservative as analgesics, rest, and physical therapy. Surgical as decompressive laminectomy, laminectomy and fusion.

They fill the space between the vertebral arches from the axis to the sacrum. They stretch from the inner surface and lower border of the vertebral arch to the external surface and upper border of the arch of the next lower vertebra, and their anterior edges limit the intervertebral foramen from the back. The ligamenta flava are made up of vertically running elastic bands lending them a yellow color. They are strongest at lumbar segment. The ligamenta flava are very elastic, as a result of which they become shorter in extension of the trunk and act like muscles, holding the trunk in extension and relieving the tension of the muscles. In flexion, they stretch and in this way, also relieve the tension of the erector muscle of the spine (Abbas et al., 2010).

The strength characteristics of the various ligaments differ from ligament to ligament as well as from region to region.
The effectiveness of a ligament is determined by its intrinsic morphology and the length of the moment arm through which it acts (Altinkaya et al., 2011). The moment arm is the perpendicular distance between the force vector (the force and its direction as applied by the ligament) and the IAR (instantaneous axis of rotation). Thus, a weaker ligament with a longer moment arm may be just as effective as a stronger one acting through a shorter moment arm. The interspinous ligament is not substantial and is often absent at the L5-S1 level and deficient at the L4-L5 level, but its significant moment arm length provides a substantial mechanical advantage. The ligamentum flavum is a complex strong ligament. It's more ventral site of attachment and resultant shorter moment arm provide less flexion resistance. It is deficient in the midline, facilitating surgical exposure of the epidural space.

Causes of spinal canal stenosis include central stenosis due to disc collapse and thickened LF, lateral or root canal stenosis, degenerative spondylolisthesis, metabolic causes, iatrogenic stenosis, spinal tumors, injury, Paget's disease of bone, achondroplasia.

Diagnosis usually depends on clinical, physical and neurological examination then confirmed by spine $\mathrm{x}$ ray, computed topography, magnetic resonance imaging, electromyelography, CT myelogram and bone scan. Other diagnostic tools include spinal nerve block and epidural steroids injections.

Treatment options include conservative as analgesics, rest and physical therapy but surgical as decompressive laminectomy, laminotomy and fusion. 


\section{ROLE OF LIGAMENTUM FLAVECTOMY IN LUMBAR SPINAL CANAL... 359}

The present work aimed to provide an update review to determine the role of ligamentum flavectomy in lumbar spinal canal stenosis.

\section{PATIENTS AND METHODS}

This study included twenty-three patients who were operated upon by laminectomy with ligamentum flavectomy as a step of decompression for managing lumbar spinal canal stenosis from August 2018 till August 2019, to evaluate the effectiveness and role of ligamentum flavectomy in lumbar spinal canal stenosis. This work was managed in ELSayed Galal University and EL-Haram specialized hospitals.

The diagnosis was based on clinical picture and radiological findings.

\section{Inclusion criteria:}

1. Age: Above 40 years to 70 years.

2. Patients with no improvement after 8 weeks failed conservative measures.

3. Imaging diagnostic evidence.

\section{Exclusion criteria:}

1. Extremes of age

2. Significant comorbidities as infection, tumors and uncontrolled diabetes.

3. Associated instability.

4. Pregnancy or suspected pregnancy

5. Local skin infection.

6. Hemorrhagic diseases.

7. Acute lumbar Fracture diagnosed by History, examination and $\mathrm{x}$-ray lumbosacral.
All patients enrolled in the study were subjected to full history, general and local examination, and investigations including $\mathrm{x}$-ray and MRI of lumbosacral spine.

Evaluation of pain severity and functional outcome:

Precise assessment of the severity of back and leg pain and the functional condition of the patient before the procedure was compared with the postoperative results.

\section{A. The Visual analogue scale "VAS":}

It is a scale from 0 to 10 where 0 means no pain at all and 10 means the worst pain. Every patient choose a number on the scale once for his back pain and another for his leg pain and to be repeated within 6 weeks and then within 3 months' post-operatively (Brown et al., 2011).

\section{B. The Oswestry Disability index:}

It was used to evaluate the functional condition of the patient's back. Each section is scored on a $0-5$ scale, 5 representing the greatest disability. The index was calculated by dividing the added score by the total possible score, which was then multiplied by 100 and expressed as a percentage. Thus, for every question not answered, the denominator is reduced by 5 (Fairbank et al., 2009).

\section{Ethical considerations:}

-Written informed consents were obtained from the Participants before the procedure starts which will include:

- $\quad$ The purpose of the study

- Methods that will be used

- The benefits

- The probable risks 
- Alterative of not participating in the study

- Confidentiality

- Right to withdraw

- Who will contact

\section{Statistical analysis:}

Recorded data were analyzed using the statistical package for social sciences, version 20.0 (SPSS Inc., Chicago, Illinois, USA). Quantitative data were expressed as mean \pm standard deviation (SD). Qualitative data were expressed as frequency and percentage.

\section{RESULTS}

This study was carried out as an interventional prospective study on 23 patients with lumbar spinal canal stenosis. Study was conducted in orthopedic surgery departments, EL-Sayed Galal University and EL-Haram specialized hospitals and aimed at assessment of the role of ligamentum flavectomy in lumbar spinal canal stenosis.

The mean age was $50.5 \pm 5.7$ years ranging from 41 to 59 years and according to gender distribution, they were $13(56.5$ $\%)$ males and $10(43.5 \%)$ females (Table 1).

Table (1): Demographic data among the patients

\begin{tabular}{|l|l|c|c|}
\hline \multirow{2}{*}{ Age (years) } & Mean \pm SD & \multicolumn{2}{|c|}{$50.5 \pm 5.7$} \\
Range & \multicolumn{2}{|c|}{$41-59$} \\
\hline \multirow{2}{*}{ Gender } & Male & 13 & $56.5 \%$ \\
\cline { 2 - 4 } & Female & 10 & $43.5 \%$ \\
\hline
\end{tabular}

There was no gait or postural abnormalities among the patients. The BMI ranged from 26 to 32 with mean
$28.96 \pm 1.94 \mathrm{~kg} / \mathrm{m} 2.19(82.6 \%)$ were overweight, and $4(17.4 \%)$ were obese (Fig. 1).

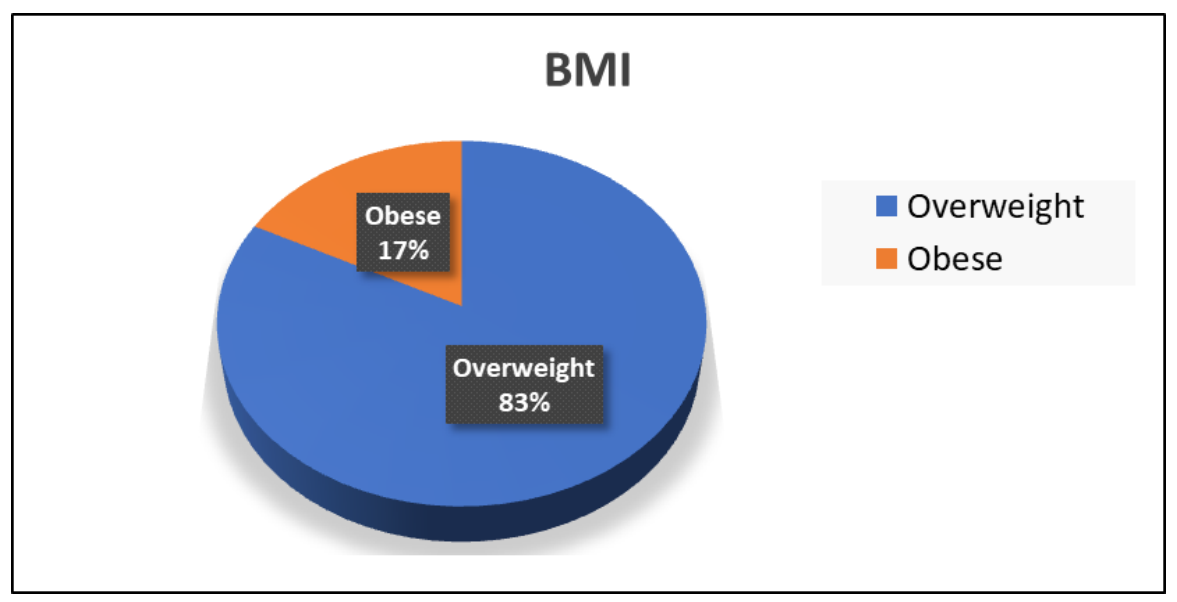

Fig. (1): BMI of the patients

The preoperative VAS ranged between 5-9 with mean $6.8 \pm 1.4$. Six weeks after operation, its range became between 1-5 with mean $2.8 \pm 0.98$. Twelve weeks later, the range was between 1-3 with mean 1.7 \pm 0.7 (Fig. 2). 
ROLE OF LIGAMENTUM FLAVECTOMY IN LUMBAR SPINAL CANAL... 361

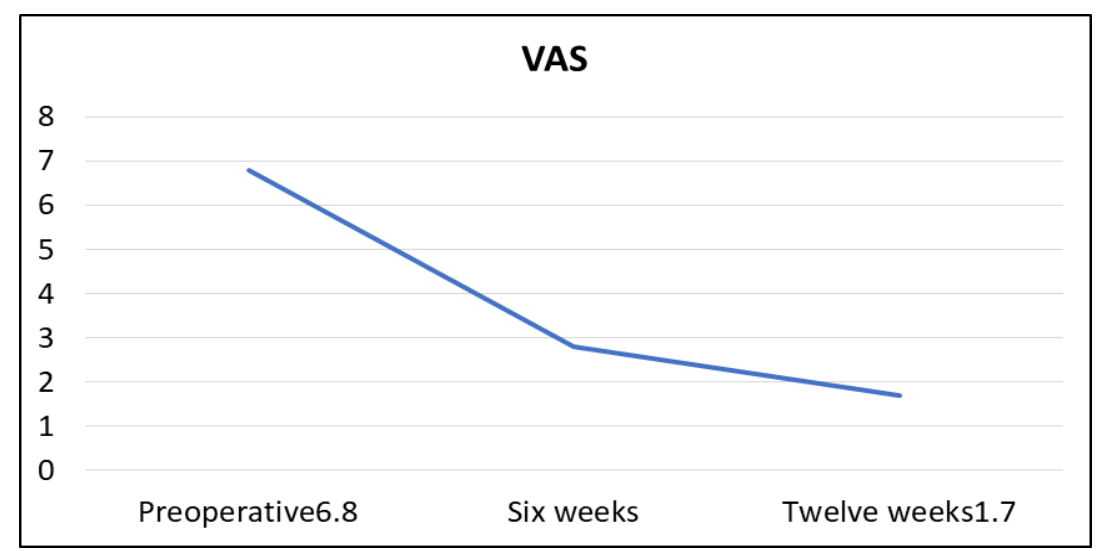

Fig. (2): The VAS of the patients' pre and postoperatively

The preoperative ODI ranged between 3-46 with mean $19.56 \pm 19.65$. Six weeks later, the range between 1-18 with mean
$7.3 \pm 7.26$. At twelve weeks, the range was between $1-15$ with mean $4.2 \pm 8.86$ (Fig. 3).

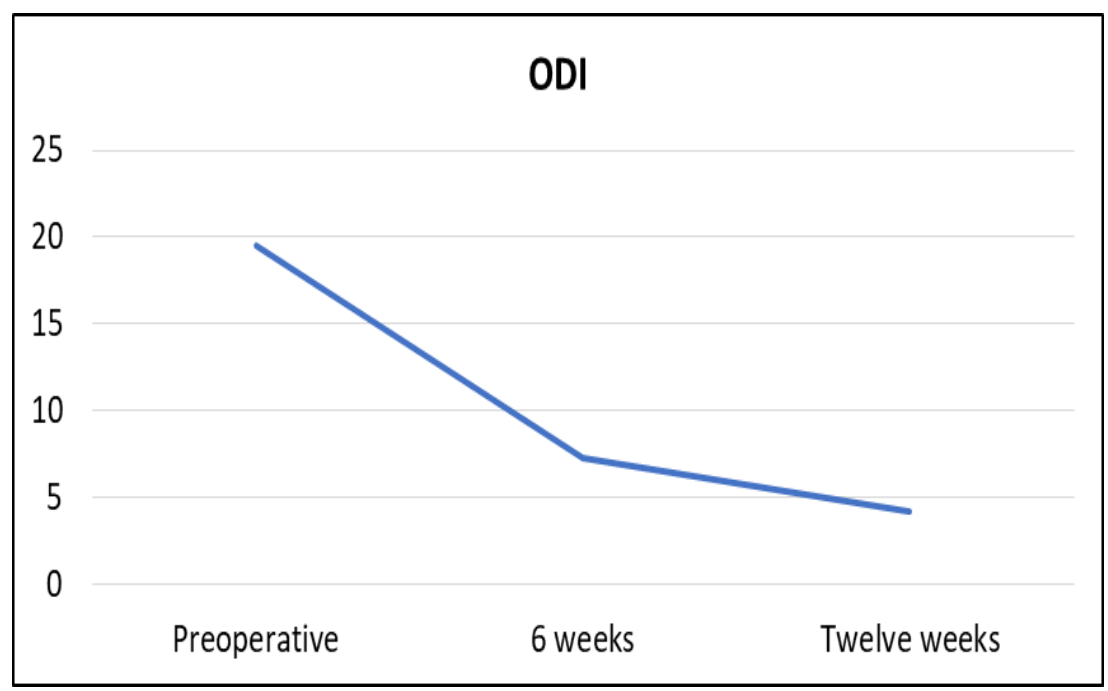

Fig. (3): The ODI of the patients' pre and postoperatively

At level L4/L5, ten patients $(43.48 \%)$ have lumbar stenosis. At L3/L4 and L4/L5 levels seven patients $(30.43 \%)$, and at
L2/L3, L3/L4, L4/L5 levels six patients $(26.1 \%)$ have stenosis (Fig. 4).

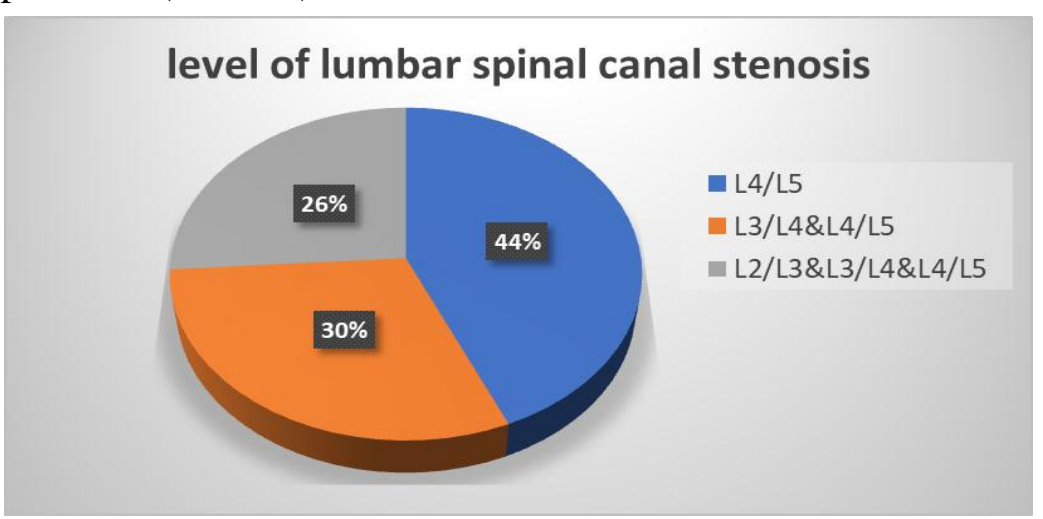

Fig. (4): The level of lumbar spinal canal stenosis 
Eight patients $(34.8 \%)$ have no leg pain, three patients have unilateral leg pain (13\%), and twelve patients (52. 2\%) have bilateral leg pain (Fig. 5).

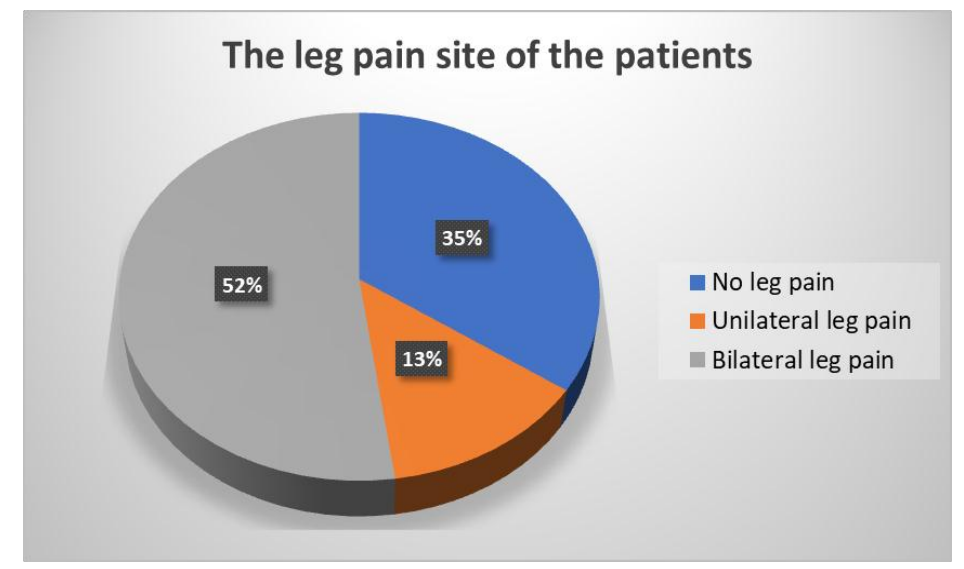

Fig. (5): The leg pain site of the patients.

\section{DISCUSSION}

This study was carried out as an interventional prospective study on 23 patients with lumbar spinal canal stenosis. Study was conducted in orthopedic surgery departments; El-Sayed Galal University and El-Haram specialized Hospitals from August 2018 till August 2019, and aimed at assessment of the role of ligamentum flavectomy in lumbar spinal canal stenosis. The mean age of the patients was $50.5 \pm 5.7$ years. The male to female ratio was 13:10.

The number of patients in our study was limited by rate of cases available in our causality during the time of our work.

Won-Seok et al. (2013) stated that the mean age of the patients was 64 years (range from 47 to 79 years), and 78 patients were male. In total, mean preoperative and postoperative VAS for leg pain (at 2-3 years postoperatively) were 7.3 and 2.8 , and mean preoperative and postoperative (at final follow-up) ODI were 53.8 and $24.7 \%$.
Wen-Jiunn et al. (2014) stated that the patients ranged in age from 47 to 97 years and were mostly $(75 \%)$ female. The VAS before surgery was $6.8 \pm 1.3$ and after 3 years was $1.8 \pm 1.0$. ODI score before surgery was $30.8 \pm 5.8$ and after 3 years was $9.4 \pm 5.9$.

Young et al. (2015) examined 19 patients (mean age, 67.9 years; 2 men and 17 women) who were treated using the Semi-Circumferential Decompression method for a lumbar spinal stenosis with degenerative spondylolisthesis. The mean VAS score of back pain decreased from 6.3 to 4.3 , and the mean VAS score for lower leg radiating pain also decreased from 8.3 to 2.5 . The average ODI score (maximum, 45 points) improved significantly from 25.3 preoperatively to 10.3 postoperatively.

Komp et al. (2015) stated that 135 patients with microsurgical or fullendoscopic decompression were followed up for 2 years. One hundred thirty-five $(84.4 \%)$ patients were included in the follow-up after 2 years the remaining cases were lost. Postoperatively $72 \%$ of 


\section{ROLE OF LIGAMENTUM FLAVECTOMY IN LUMBAR SPINAL CANAL... 363}

the patients no longer had leg pain or the pain was almost completely reduced and $21.2 \%$ experienced occasional pain.

\section{CONCLUSION}

Ligamentum flavectomy is an essential step in all surgical management of lumbar spinal canal stenosis for decompression of spinal canal.

\section{REFERENCES}

1. Abbas J, Hamoud K, Masharawi YM, May H, Hay O, Medlej B, Peled $N$ and Hershkovitz I (2010): Ligamentum flavum thickness in normal and stenotic lumbar spines. Spine, 35:1225-1248.

2. Altinkaya N, Yildirim T, Demir S, Alkan O and Sarica FB (2011): Factors associated with the thickness of the ligamentum flavum: is ligamentum flavum thickening due to hypertrophy or buckling? Spine, 36: 1093 1097.

3. Komp M, Hahn P, Oezdemir S, Giannakopoulos A, Heikenfeld R, Kasch R, Merk H, Godolias G and Ruetten S (2015): Bilateral Spinal Decompression of Lumbar Central Stenosis with the Full-Endoscopic Interlaminar Versus Microsurgical Laminotomy Technique: A Prospective, Randomized, Controlled Study. Pain Physician, 18:61-70.

4. Park J-B, Kong C-G, Suhl K-H, and Chang E-D, Riew KD (2009): the increased expression of matrix metalloproteinases associated with elastin degradation and fibrosis of the ligamentum flavum in patients with lumbar spinal stenosis. Clin Orthop Surg, $1: 81-89$.

5. Park JO, Lee BH, Kang YM, Kim TH, Yoon JY, Kim H, Kwon UH, Lee KI, Lee HM and Moon SH. (2013): Inflammatory cytokines induce fibrosis and ossification of human ligamentum flavum cells. J Spinal Disord Tech, 26: 6-12.

6. Wen-Jiunn L, Shih-Wun H, Da-Yon L, and Tung-Wu L (2014): Clinical outcomes following sublaminar-trimming laminoplasty for extensive lumbar canal stenosis. Eur Spine J., 23(1): 80-86.

7. Won-Seok C, Chang $\mathbf{H}$ and Ji Y, Shin C (2013): Spinal canal morphology and clinical outcomes of microsurgical bilateral decompression via a unilateral approach for lumbar spinal canal stenosis.Eur Spine J, DOI 10.1007/s00586-013-3116-7.

8. Young S, Choi C, Oh S, Park S and Park S (2015): Semi-Circumferential Decompression: Microsurgical Total en-bloc Ligamentum Flavectomy to Treat Lumbar Spinal Stenosis with Grade I Degenerative Spondylolisthesis. Clin Orthop Surg , 7(4): 470-475.

9. Brown A and Maydeu-Olivares A. (2011): Item response modeling of forced-choice questionnaires. Educational and Psychological Measurement. , 71:460-502.

10. Fairbank JC and Pynsent PB. (2009): The Oswestry Disability Index. Spine, 25:294052. 
دور إز الة الرباط الأصفر في ضيق قناة العمود الفقري القطني في في

كمال عبدالرحمن عبد الحافظ، محمد فتحي فهمي الحلواني، مصطفى عبدالله كمال مصطقى

\section{قسم جراحة العظام، كلية الطب، جامعة الأزهر}

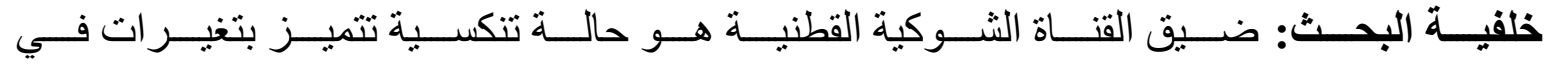

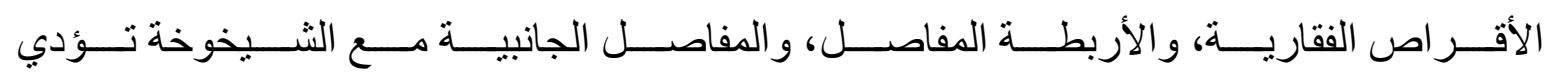

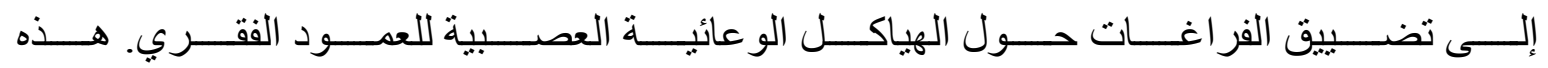

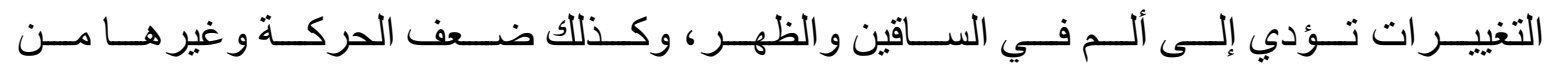

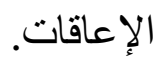

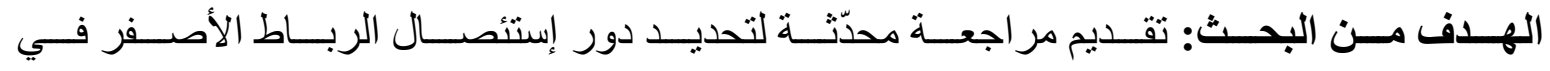
ضيق القناة الثوكية القطنية.

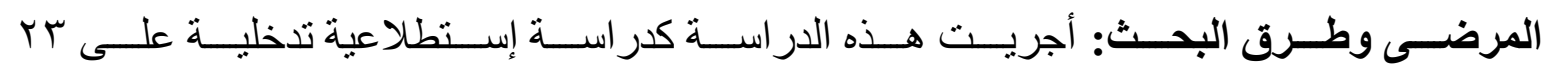

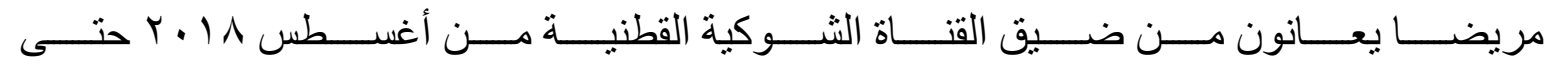

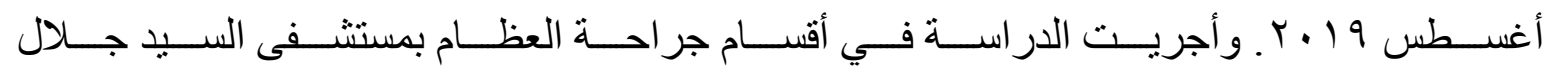

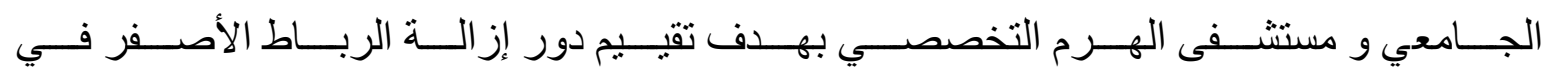
ضيق قناة العمود الفقري القطني.

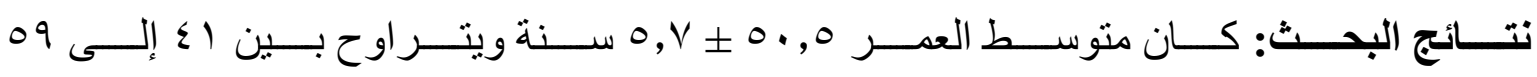

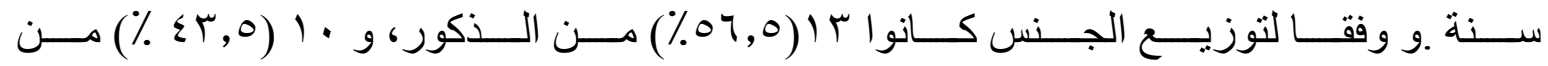

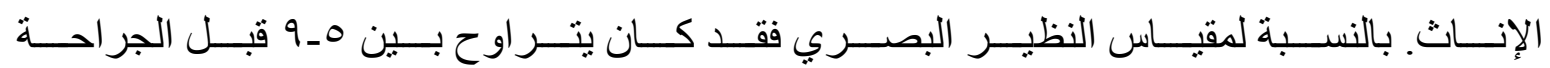

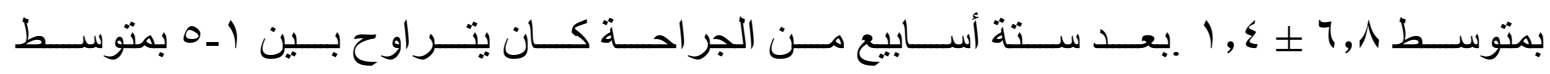

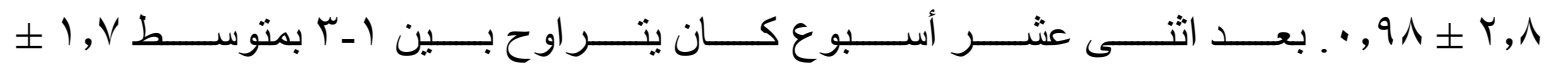

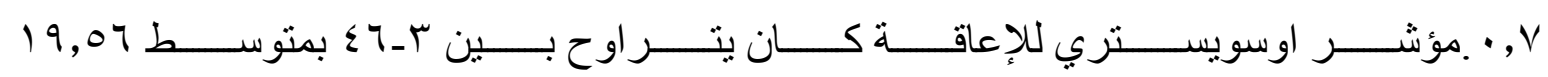

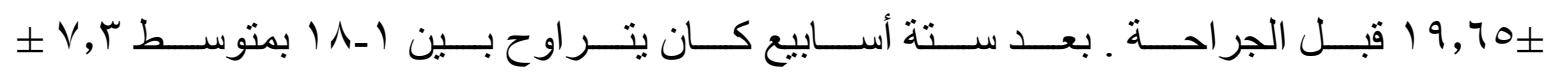

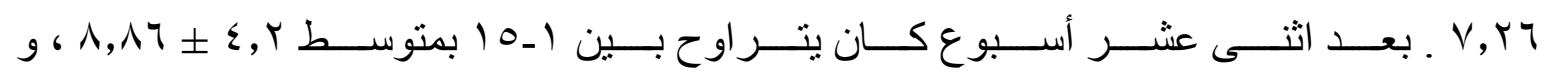

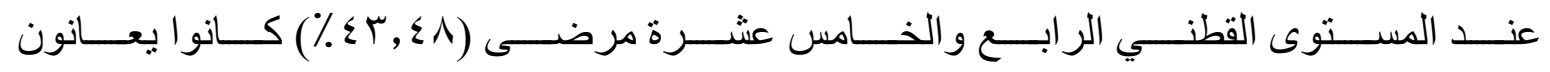


ROLE OF LIGAMENTUM FLAVECTOMY IN LUMBAR SPINAL CANAL... 365

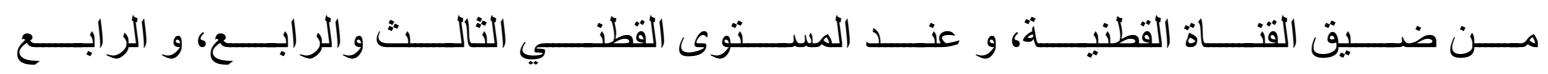

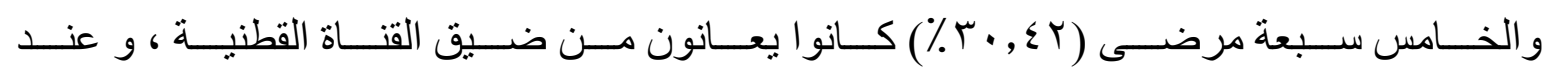

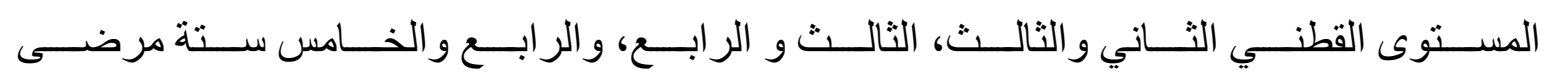

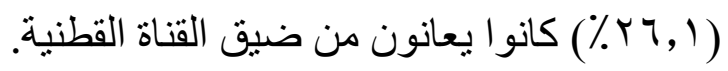

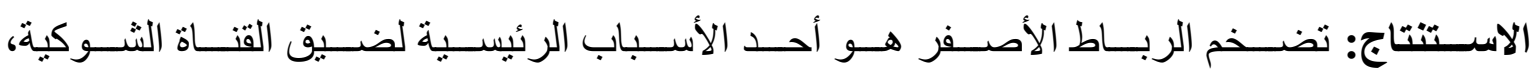

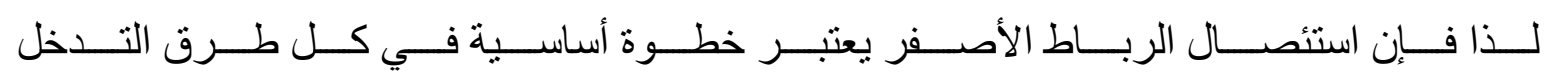
الجر احي لضيق القناة الشوكية القطنية من أجل تخفيف الضغط عن القناة الشوكية. 